Communication

\title{
Selective Controlled/Living Photoradical Polymerization of Glycidyl Methacrylate, Using a Nitroxide Mediator in the Presence of a Photosensitive Triarylsulfonium Salt
}

\section{Eri Yoshida}

Department of Environmental and Life Sciences, Toyohashi University of Technology, 1-1 Hibarigaoka, Tempaku-cho, Toyohashi, Aichi 441-8580, Japan; E-Mail: eyoshida@ens.tut.ac.jp; Tel.: +81-532-44-6814; Fax: +81-532-48-5833

Received: 23 July 2012; in revised form: 10 August 2012 / Accepted: 30 August 2012 / Published: 10 September 2012

\begin{abstract}
The controlled/living photoradical polymerization of glycidyl methacrylate (GMA) was attained using 4-methoxy-2,2,6,6-tetramethylpiperidine-1-oxyl (MTEMPO) as the mediator and (2RS,2'RS)-azobis(4-methoxy-2,4-dimethylvaleronitrile) as the initiator in the presence of (4-tert-butylphenyl)diphenylsulfonium triflate $\left({ }^{t} \mathrm{BuS}\right)$. Whereas the polymerization in the absence of MTEMPO yielded a gel-containing polymer, the MTEMPO-mediated polymerization produced poly(GMA) bonded at the vinyl site, and retained the oxirane ring structure. No occurrence of the cationic ring-opening photopolymerization of the oxirane ring even in the presence of the photosensitive onium salt indicated that ${ }^{t} \mathrm{BuS}$ served as the photoelectron transfer agent between MTEMPO in their excited states at the propagating chain end. The resulting polymers had comparatively narrow molecular weight distributions of $M_{\mathrm{w}} / M_{\mathrm{n}}=1.46-1.48$. The living nature of the MTEMPO-mediated polymerization was confirmed on the basis of a linear increase in the conversion-molecular weight plots and gel permeation chromatography (GPC) analysis.
\end{abstract}

Keywords: photopolymerization; controlled/living radical polymerization; vinyl group; glycidyl methacrylate; oxirane ring; 4-methoxy-2,2,6,6-tetramethylpiperidine-1-oxyl; cationic ring-opening photopolymerization; (4-tert-butylphenyl)diphenylsulfonium triflate; (2RS,2'RS)-azobis(4-methoxy-2,4-dimethylvaleronitrile) 


\section{Introduction}

Poly(glycidyl methacrylate) (PGMA) and its copolymers have various industrial applications, such as coatings, adhesives, printing-ink, photo imaging [1], enzyme immobilization [2], and carbon dioxide fixation [3] based on the highly reactive pendant oxirane rings that provide the sequential ring-opening reactions. The oxirane rings have also attracted considerable attention from the viewpoint of the photopolymerization chemistry. Monomers, for instance, cyclohexene oxide, $n$-butyl glycidyl ether, and phenyl glycidyl ether undergo cationic ring-opening photopolymerization in the presence of photosensitive onium salts, such as the diaryliodonium [4-7], triarylsulfonium [6-8], and ferrocenium salts [1,9]. The cationic photopolymerization of such oxirane monomers is initiated by the strong Brønsted acid generated through the photolysis of these salts.

While the photosensitive onium salts play the role of the photo-acid generator of the initiator for the cationic ring-opening photopolymerization of the oxirane monomers, it has been reported that these onium salts serve as an accelerator for the controlled/living photoradical polymerization of methacrylate monomers using 4-methoxy-2,2,6,6-tetramethylpiperidine-1-oxyl (MTEMPO) as the mediator [10-24]. MTEMPO has high solubility both in organic solvents and water compared with 2,2,6,6-tetramethylpiperidine-1-oxyl (TEMPO) and is a model compound of TEMPO supported on a polymer by ether linkage $[25,26]$. During this photoradical polymerization, it has been suggested that the onium salts enhance the polymerization rate by promoting the dissociation of MTEMPO and the propagating radical at the chain end through the reversible electron transfer from MTEMPO to the onium salt in the excited state [12,19,22]. It was demonstrated that MTEMPO controlled the propagating radical at the chain end as well as the MTEMPO-mediated thermal polymerization based on the fact that the resulting polymer had the MTEMPO moiety at the chain end [11]. The electron transfer from MTEMPO to the onium salt has not been directly proved, however, this mechanism is supported by many electron transfer reactions from the electron donors to the onium salts [27-29] and by the electrochemical potentials of TEMPO [30-32] and the onium salts [33-35].

It was found that GMA selectively underwent controlled/living photoradical polymerization at the vinyl group using the MTEMPO mediator in the presence of the photosensitive onium salt, rather than the cationic ring-opening photopolymerization of the oxirane ring. This paper describes the controlled/living photoradical polymerization of GMA using MTEMPO as the mediator in the presence of the photosensitive (4-tert-butylphenyl)diphenylsulfonium triflate ( $\left.{ }^{t} \mathrm{BuS}\right)$.

\section{Results and Discussion}

The photoradical polymerization of GMA was performed using $r$-AMDV as the initiator and MTEMPO as the mediator in the presence of ${ }^{t} \mathrm{BuS}$ at the molar ratios of MTEMPO/r-AMDV $=1.06$ and ${ }^{t} \mathrm{BuS} / \mathrm{MTEMPO}=0.530$. The bulk polymerization was carried out at room temperature by irradiation using a high-pressure mercury lamp. The orange-colored solution turned colorless within $2 \mathrm{~h}$. After an $8 \mathrm{~h}$ polymerization, the stirrer bar stopped rotating, and a solid product was obtained. The monomer conversion was estimated to be $58 \%$ by ${ }^{1} \mathrm{H}$ NMR using the signal intensity at $3.9-3.7 \mathrm{ppm}$ (the polymer, $\mathbf{c}^{\prime}$ ) and $4.00 \mathrm{ppm}$ (the monomer, $\mathbf{C}^{\prime}$ ) for one of the two non-equivalent protons of the methylene attached to the ester oxygen (Figure 1). The polymerization produced a polymer with the 
molecular weight of $M_{\mathrm{n}}=13,300$ and its distribution of $M_{\mathrm{w}} / M_{\mathrm{n}}=1.48$. On the other hand, the polymerization in the absence of MTEMPO rapidly proceeded to yield a polymer at a $100 \%$ conversion within $30 \mathrm{~min}$, however, the resulting polymer contained gel. The molecular weight and its distribution for a THF-soluble part of the gel-containing polymer were $M_{\mathrm{n}}=58,700$ and $M_{\mathrm{w}} / M_{\mathrm{n}}=5.08$, respectively. This gel production indicates that the uncontrolled polymerization occurred at both the groups; the radical polymerization of the vinyl group and the cationic ring-opening polymerization of the oxirane ring.

Figure 1. The ${ }^{1} \mathrm{H}$ NMR spectrum of the product containing the monomer and resulting polymer obtained by the MTEMPO-mediated photopolymerization. Solvent: $\mathrm{CDCl}_{3}$.
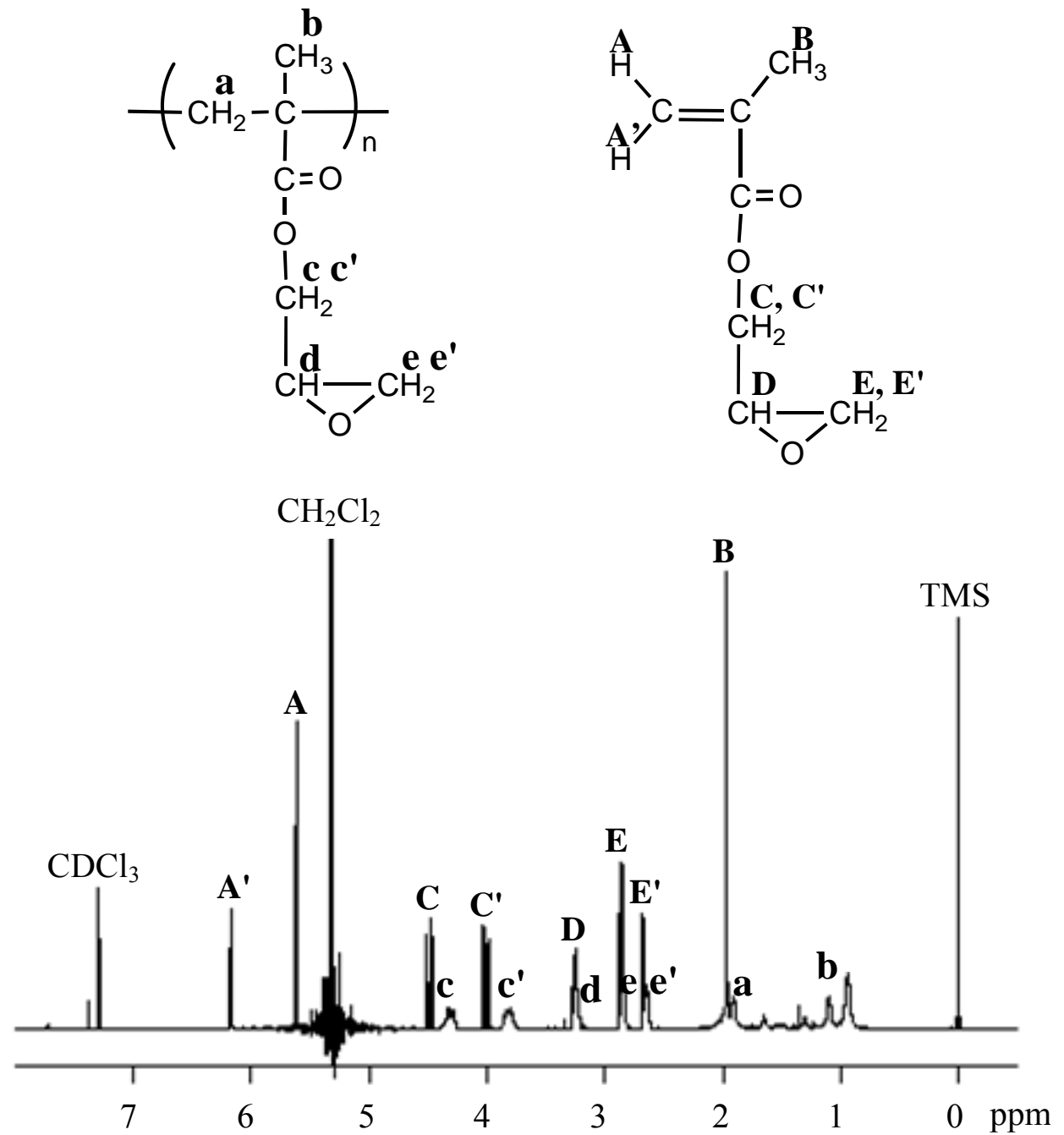

The ${ }^{1} \mathrm{H}$ NMR analysis revealed that the MTEMPO-mediated polymerization selectively proceeded at the vinyl group, retaining the oxirane ring. Figure 2 shows the ${ }^{1} \mathrm{H}$ NMR spectrum of the polymer obtained by the MTEMPO-mediated polymerization. Signals originating from the two non-equivalent protons (c and $\mathbf{c}^{\prime}$ ) of the methylene bonded to the ester oxygen were observed at 4.4-4.2 ppm and 3.9-3.7 ppm. A signal attributed to the methine proton (d) of the oxirane ring was discerned at 3.3-3.2 ppm, while two non-equivalent proton signals (e and $\left.\mathbf{e}^{\prime}\right)$ for the methylene of the ring were observed at 2.9-2.8 ppm (trans) and 2.7-2.6 ppm (cis). The signals at 2.3-1.4 ppm and 1.4-0.7 ppm were based on the methylene (a) and methyl protons (b) of the main chain. These assignments agreed 
with those for PGMA obtained by the RAFT and free radical polymerizations of the vinyl group [36,37]. The presence of the oxirane rings in the polymer structure and good agreement in the ratio of the respective signal intensity with the PGMA structure obtained by the polymerization of the vinyl group indicate that no occurrence of the cationic ring-opening polymerization of the oxirane rings. It has been reported that the triarylsulfonium salt serves as a photoinitiator for the cationic ring-opening polymerization of oxirane monomers [6-8]. The structure of the PGMA polymerized at the vinyl group indicates that ${ }^{t} \mathrm{BuS}$ served as the photoelectron transfer agent for the MTEMPO-mediated polymerization, rather than as the photoinitiator for the cationic ring-opening polymerization of the oxirane ring. The proposed mechanism is shown in Scheme $1 .{ }^{t} \mathrm{BuS}$ should enhance the polymerization rate by reversibly transferring an electron between MTEMPO and the onium salt. In addition, the MTEMPO-mediated polymerization in the absence of ${ }^{t} \mathrm{BuS}$ slowly proceeded to produce a polymer at a $38 \%$ conversion for $8 \mathrm{~h}\left(M_{\mathrm{n}}=11,000, M_{\mathrm{w}} / M_{\mathrm{n}}=1.48\right)$.

Figure 2. The ${ }^{1} \mathrm{H}$ NMR spectrum of the poly(glycidyl methacrylate) (PGMA) obtained by the MTEMPO-mediated photopolymerization. Conversion $=58 \%, M_{\mathrm{n}}=13,300$, $M_{\mathrm{w}} / M_{\mathrm{n}}=1.48$. Solvent: $\mathrm{CDCl}_{3}$.

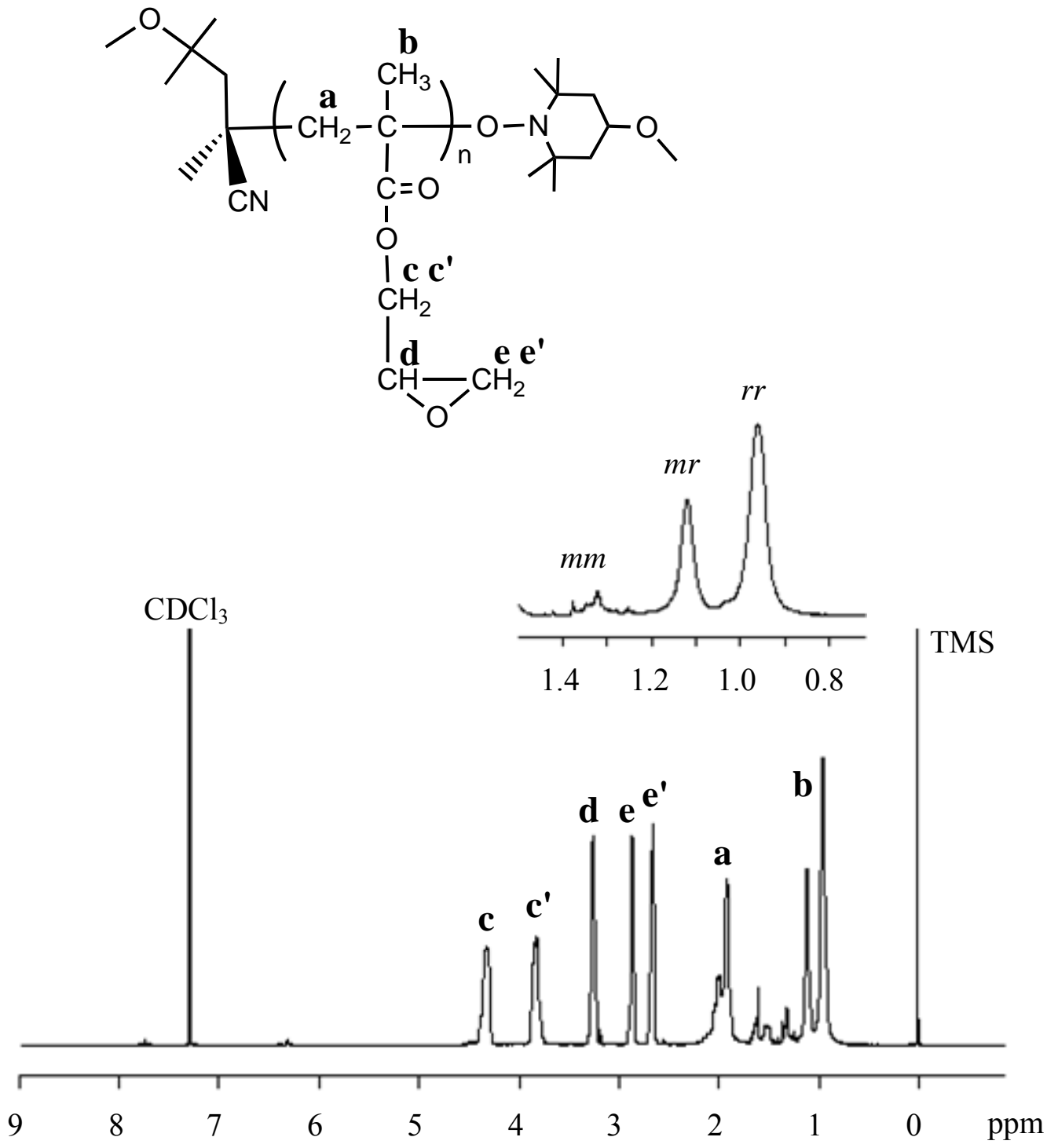


Scheme 1. The proposed mechanism of the MTEMPO-mediated photopolymerization of glycidyl methacrylate (GMA).

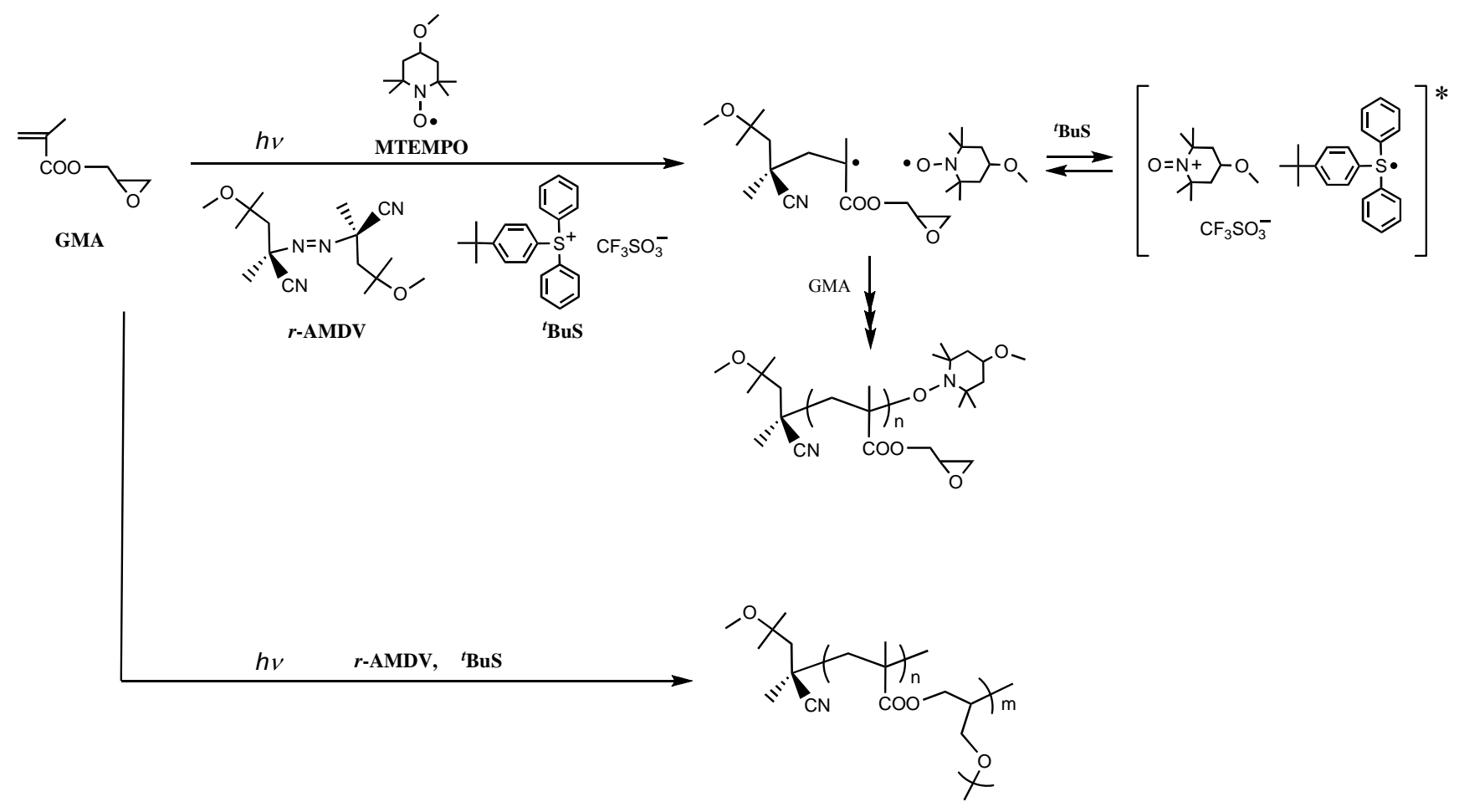

The tacticity of the PGMA obtained by the MTEMPO-mediated photopolymerization was estimated to be $\mathrm{mm} / \mathrm{mr} / \mathrm{rr}=6 / 31 / 63$ based on the signal intensity at $1.36-1.19 \mathrm{ppm}$ for $\mathrm{mm}, 1.19-1.02 \mathrm{ppm}$ for $m r$, and 1.02-0.73 ppm for $r r$. This syndiotactic-rich proportion was similar to that of the poly(methyl methacrylate) $\left(\mathrm{mm} / \mathrm{mr} / \mathrm{rr}=3 / 28 / 69\right.$ for a $58 \%$ conversion, $\left.M_{\mathrm{n}}=11,300, M_{\mathrm{w}} / M_{\mathrm{n}}=1.43\right)$ obtained by the MTEMPO-mediated polymerization under identical conditions [14].

In order to evaluate the livingness of the polymerization, the correlation between the monomer conversion and the molecular weight of the resulting polymers was investigated. Figure 3 shows the gel permeation chromatography (GPC) profiles of the polymers obtained by the polymerization for $4 \mathrm{~h}$ (conversion $=17 \%), 5 \mathrm{~h}(43 \%)$, and $8 \mathrm{~h}(58 \%)$. The curves were shifted to the higher molecular weight side with an increase in the conversion, implying the living nature of the polymerization. It is suggested that the MTEMPO-mediated photoradical polymerization of GMA in the presence of ${ }^{t} \mathrm{BuS}$ selectively proceeded at the vinyl group in accordance with a controlled/living mechanism.

The correlation of the conversion and the molecular weight of the polymer is shown in Figure 4. The molecular weight linearly increased versus the conversion, although the line for the plots did not pass through zero. This phenomenon can be accounted for by the previous study of the MTEMPO-mediated polymerization; oligomers are formed under a non-steady state during the very early polymerization [12,18]. However, the molecular weight distribution remained at around 1.4 during the polymerization. The linear increase in the conversion-molecular weight plots and constant molecular weight distribution imply a controlled/living mechanism of the polymerization. 
Figure 3. Gel permeation chromatography (GPC) profiles of the PGMA for each conversion: $17 \%(4 \mathrm{~h}), 43 \%(5 \mathrm{~h})$, and $58 \%(8 \mathrm{~h})$ from the right.

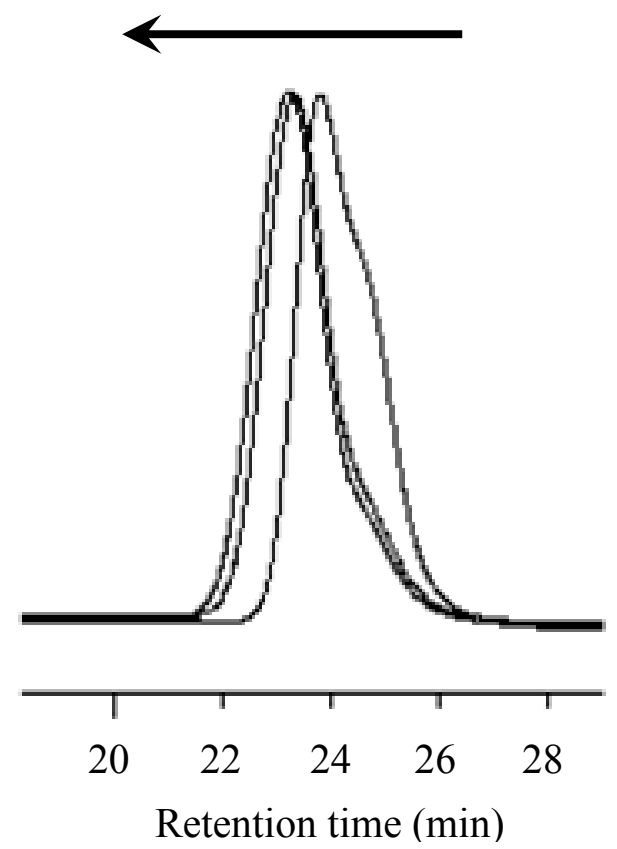

Figure 4. The plots of the molecular weight and its distribution vs. the conversion for the MTEMPO-mediated photopolymerization of GMA. MTEMPO $/ r-\mathrm{AMDV}=1.06$, ${ }^{t} \mathrm{BuS} / \mathrm{MTEMPO}=0.53$. Where ${ }^{t} \mathrm{BuS}$ was (4-tert-butylphenyl)diphenylsulfonium triflate, $r$-AMDV was (2RS,2'RS)-Azobis(4-methoxy-2,4-dimethylvaleronitrile.

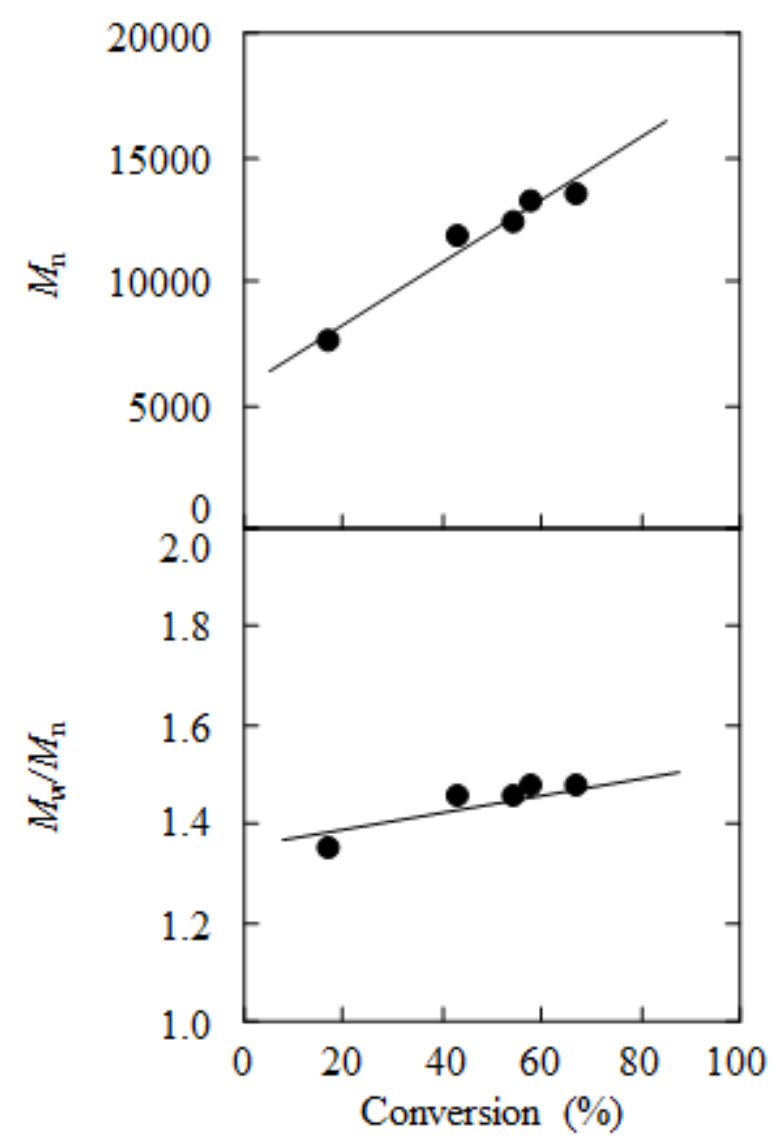




\section{Experimental Section}

Instrumentation: The photopolymerization was carried out using a Wacom HX-500 illuminator with a $500 \mathrm{~W}$ high-pressure mercury lamp (BMO-500D1, Wacom Co. Ltd.). Gel permeation chromatography (GPC) was performed using a Tosoh GPC-8020 instrument equipped with a DP-8020 dual pump, a CO-8020 column oven, and a RI-8020 refractometer. Three polystyrene gel columns, Tosoh TSKGEL $\mathrm{G} 2000 \mathrm{H}_{\mathrm{XL}}, \mathrm{G} 4000 \mathrm{H}_{\mathrm{XL}}$, and $\mathrm{G} 6000 \mathrm{H}_{\mathrm{XL}}$ were used with tetrahydrofuran (THF) as the eluent at $40{ }^{\circ} \mathrm{C}$. ${ }^{1} \mathrm{H}$ NMR measurements were conducted using Varian 300 and Jeol ECS 400 FT NMR spectrometers.

Materials: (2RS,2'RS)-Azobis(4-methoxy-2,4-dimethylvaleronitrile) ( $r$-AMDV) was obtained by separation from a mixture of the racemic and meso forms of 2,2'-azobis(4-methoxy-2,4-dimethylvaleronitrile) [38]. MTEMPO was prepared as reported previously [39]. GMA was distilled over calcium hydride under reduced pressure. ${ }^{t} \mathrm{BuS}$ was purchased from Sigma-Aldrich and used as received.

MTEMPO-mediated photopolymerization: General procedure GMA (1.042 g, 7.33 mmol), $r$-AMDV (14.0 mg, $0.0454 \mathrm{mmol})$, MTEMPO (9.0 mg, $0.0483 \mathrm{mmol})$, and ${ }^{t} \mathrm{BuS}(12.0 \mathrm{mg}$, $0.0256 \mathrm{mmol}$ ) were placed in an ampoule. The contents were degassed the contents several times by a freeze-pump-thaw cycle, and the ampoule was sealed under vacuum. The bulk polymerization was carried out at room temperature for $8 \mathrm{~h}$ with irradiation by reflective light using a mirror with a $500 \mathrm{~W}$ high-pressure mercury lamp. Dichloromethane $(10 \mathrm{~mL})$ was added to the product to dissolve it. Part of the dichloromethane solution $(1 \mathrm{~mL})$ was withdrawn using a syringe to determine the conversion by ${ }^{1} \mathrm{H}$ NMR. The residual solution was concentrated by an evaporator to $c a .3 \mathrm{~mL}$ and was poured into methanol $(500 \mathrm{~mL})$ to isolate a polymer. The precipitates were collected by filtration and dried in vacuo for several hours to obtain a polymer (594.0 mg).

Photopolymerization in the absence of MTEMPO: GMA (1.042 g, $7.33 \mathrm{mmol}), r$-AMDV (14.0 mg, $0.0454 \mathrm{mmol})$, and ${ }^{t} \mathrm{BuS}(12.0 \mathrm{mg}, 0.0256 \mathrm{mmol})$ were placed in an ampoule. The contents were degassed the contents several times by a freeze-pump-thaw cycle, and the ampoule was sealed under vacuum. The bulk polymerization was carried out at room temperature for $30 \mathrm{~min}$ with irradiation by reflective light using a mirror with a $500 \mathrm{~W}$ high-pressure mercury lamp. Dichloromethane $(10 \mathrm{~mL})$ was added to the gel-containing product to swell it. The product was poured into methanol $(500 \mathrm{~mL})$ to isolate a polymer. The precipitates were collected by filtration and dried in vacuo for several hours to obtain a polymer $(1.047 \mathrm{~g})$. The conversion was estimated gravimetrically.

\section{Conclusions}

The controlled/living photoradical polymerization of GMA was attained using the MTEMPO mediator in the presence of ${ }^{t} \mathrm{BuS}$. The polymerization selectively proceeded in a radical manner to produce a polymer bonded at the vinyl site. No occurrence of the cationic ring-opening photopolymerization of the oxirane ring even in the presence of the onium salt indicated that the onium salt did not serve as the photo-acid generator, but as the photoelectron transfer agent between MTEMPO in the excited state at the propagating chain end. This electron transfer from MTEMPO to the onium salt resulted in enhancement of the polymerization rate. The living nature of the polymerization was confirmed on the basis of the linear increase in the conversion-molecular weight plots, coupled with the constant molecular weight distribution, and GPC analysis. 


\section{Acknowledgments}

The author is thankful for Shiseido Female Researcher Science Grant.

\section{References}

1. Meier, K.; Zweifel, H. Imaging with iron arene photoinitiators. J. Imag. Sci. 1986, 30, 174-177.

2. Xu, F.; Cai, Q.; Li, Y.; Kang, E.; Neoh, K.G. Covalent immobilization of glucose oxidase on well-defined poly(glycidyl methacrylate)-Si(111) hybrids from surface-initiated atom-transfer radical polymerization. Biomacromolecules 2005, 6, 1012-1020.

3. Kihara, H.; Endo, T. Incorporation of carbon dioxide into poly(glycidyl methacrylate). Macromolecules 1992, 25, 4824-4825.

4. Crivello, J.V. Cationic photopolymerization of alkyl glycidyl ethers. J. Polym. Sci. A Polym. Chem. 2006, 44, 3036-3052.

5. Crivello, J.V. Design and synthesis of multifunctional glycidyl ethers that undergo frontal polymerization. J. Polym. Sci. A Polym. Chem. 2006, 44, 6435-6448.

6. Crivello, J.V. The discovery and development of onium salt cationic photoinitiators. J. Polym. Sci. A Polym. Chem. 1999, 37, 4241-4254.

7. Lazauskaite, R.; Stanislovaityte, E.; Grazulevicius, J.V. Cationic photopolymerization of 1,3-di(9-carbazolyl)-2-propanol glycidyl ether. Monatsh. Chem. 2008, 139, 887-893.

8. Ionescu-Vasii, L.L.; Dimonie, M.D.; Abadie, M.J.M. Kinetic model of photoinitiated polymerization of phenyl glycidyl ether monomer. Polym. Int. 2008, 47, 221-225.

9. Meier, K.; Zweifel, H. Photoinitiated cationic polymerization of epoxides with iron-arene complexes. J. Rad. Curing 1986, 13, 26-32.

10. Yoshida, E. Photo-living radical polymerization of methyl methacrylate by a nitroxide mediator. Colloid Polym. Sci. 2008, 286, 1663-1666.

11. Yoshida, E. Photo-living radical polymerization of methyl methacrylate by 2,2,6,6-tetramethylpiperidine-1-oxyl in the presence of a photo-acid generator. Colloid Polym. Sci. 2009, 287, 767-772.

12. Yoshida, E. Photo-living radical polymerization of methyl methacrylate using alkoxyamine as an initiator. Colloid Polym. Sci. 2010, 288, 7-13.

13. Yoshida, E. Nitroxide-mediated photo-living radical polymerization of vinyl acetate. Colloid Polym. Sci. 2010, 288, 73-78.

14. Yoshida, E. Nitroxide-mediated photo-living radical polymerization of methyl methacrylate using (4-tert-butylphenyl)diphenylsulfonium triflate as a photo-acid generator. Colloid Polym. Sci. 2010, 288, 239-243.

15. Yoshida, E. Effect of azoinitiators on nitroxide-mediated photo-living radical polymerization of methyl methacrylate. Colloid Polym. Sci. 2010, 288, 341-345.

16. Yoshida, E. Effects of initiators and photo-acid generators on nitroxide-mediated photo-living radical polymerization of methyl methacrylate. Colloid Polym. Sci. 2010, 288, 901-905.

17. Yoshida, E. Stability of growing polymer chain ends for nitroxide-mediated photo-living radical polymerization. Colloid Polym. Sci. 2010, 288, 1027-1030. 
18. Yoshida, E. Nitroxide-mediated photo-living radical polymerization of methyl methacrylate in solution. Colloid Polym. Sci. 2010, 288, 1639-1643.

19. Yoshida, E. Nitroxide-mediated photo-living radical polymerization of methyl methacrylate in the presence of $\left(\eta^{6}\right.$-benzene $)\left(\eta^{5}\right.$-cyclopentadienyl)Fe ${ }^{\mathrm{II}}$ hexafluorophosphate. Colloid Polym. Sci. 2010, 288, 1745-1749.

20. Yoshida, E. Nitroxide-mediated photo-controlled/living radical polymerization of ethyl acrylate. Colloid Polym. Sci. 2011, 289, 1127-1132.

21. Yoshida, E. Nitroxide-mediated photo-controlled/living radical dispersion polymerization of methyl methacrylate. Colloid Polym. Sci. 2011, 289, 1625-1630.

22. Yoshida, E. Photo-controlled/living radical polymerization of tert-butyl methacrylate in the presence of a photo-acid generator using a nitroxide mediator. Colloid Polym. Sci. 2012, 290, 661-665.

23. Yoshida, E. Aqueous photo-living radical polymerization of sodium methacrylate using a water-soluble nitroxide mediator. Int. Sch. Res. Netw. ISRN Polym. Sci. 2012, submitted.

24. Yoshida, E. Effects of illuminance and heat rays on photo-controlled/living radical polymerization mediated by 4-methoxy-2,2,6,6-tetramethylpiperidine-1-oxyl. Int. Sch. Res. Netw. ISRN Polym. Sci. 2012, submitted.

25. Yoshida, E. Synthesis of poly(methyl methacrylate)-block-poly(tetrahydrofuran) by photo-living radical polymerization using a 2,2,6,6-tetramethylpiperidine-1-oxyl macromediator. Colloid Polym Sci. 2009, 287, 1417-1424.

26. Yoshida, E. Graft copolymerization of methyl methacrylate on polystyrene backbone through nitroxide-mediated photo-living radical polymerization. Colloid Polym. Sci. 2011, 289, 837-841.

27. Rodrigues, M.R.; Neumann, M.G. Cationic photopolymerization of tetrahydrofuran: A mechanistic study on the use of a sulfonium salt-phenothiazine initiation system. J. Polym. Sci. Polym. Chem. 2001, 39, 46-55.

28. Rodrigues, M.R.; Neumann, M.G. Mechanistic study of tetrahydrofuran polymerization photoinitiated by a sulfonium salt/thioxanthone system. Macromol. Chem. Phys. 2001, 202, 2776-2782.

29. Guo, H.; Kajiwara, A.; Morishima, Y.; Kamachi, M. Radical/cation transformation polymerization and its application to the preparation of block copolymers of p-methoxystyrene and cyclohexene oxide. Macromolecules 1996, 29, 2354-2358.

30. Endo, T.; Miyazawa, T.; Shiihashi, S.; Okawara, M. Oxidation of hydroxide ion by immonium oxide. J. Am. Chem. Soc. 1984, 106, 6732-6734.

31. Semmelhack, M.F.; Schmid, C.R. Nitroxy-mediated electrooxidation of amines to nitriles and carbonyl compounds. J. Am. Chem. Soc. 1983, 105, 3877-3878.

32. Semmelhack, M.F.; Chou, C.S.; Cortes, D.A. Nitroxy-mediated electrooxidation of aalcohols to aldehydes and ketones. J. Am. Chem. Soc. 1983, 105, 4492-4494.

33. Pappas, S.P.; Gatechair, L.R.; Jilek, J.H. Photoinitiation of cationic polymerization. III. Photosensitization of diphenyliodonium and triphenylsulfonium salts. J. Polym. Sci. Polym. Chem. 1984, 22, 77-84.

34. McKinney, P.S.; Rosenthal, S. The electrochemical reduction of the triphenylsulfonium ion. J. Electroanal. Chem. 1968, 16, 261-270. 
35. Crivello, J.V.; Sangermano, M. Visible and long-wavelength photoinitiated cationic polymerization. J. Polym. Sci. Polym. Chem. 2001, 39, 343-356.

36. Yin, H.; Zheng, H.; Lu, L.; Liu, P.; Cai, Y. Highly efficient and well-controlled ambient temperature RAFT polymerization of glycidyl methacrylate under visible light radiation. J. Polym. Sci. Polym. Chem. 2007, 45, 5091-5102.

37. Yamamoto, S.; Moriya, O.; Endo, T. Efficient fixation of carbon dioxide into poly(glycidyl methacrylate) containing pendant crown ether. Macromolecules 2003, 36, 1514-1521.

38. Kita, Y.; Gotanda, K.; Murata, K.; Suemura, M.; Sano, A.; Yamaguchi, T.; Oka, M.; Matsugi, M. Practical radical additions under mild conditions using 2,2'-azobis(2,4-dimethyl-4-methoxyvaleronitrile) [V-70] as an initiator. Org. Process Res. Dev. 1998, 2, 250-254.

39. Miyazawa, T.; Endo, T.; Shiihashi, S.; Ogawara, M. Selective oxidation of alcohols by oxoaminium salts $\left(\mathrm{R}_{2} \mathrm{~N}=\mathrm{O}^{+} \mathrm{X}^{-}\right)$. J. Org. Chem. 1985, 50, 1332-1334.

(C) 2012 by the authors; licensee MDPI, Basel, Switzerland. This article is an open access article distributed under the terms and conditions of the Creative Commons Attribution license (http://creativecommons.org/licenses/by/3.0/). 